\title{
A INFLUÊNCIA DA CONTAÇÃO DE HISTÓRIA PARA O LETRAMENTO NA ESCOLA DE EDUCAÇÃO INFANTIL FRANCISCO ARAÚJO
}

\author{
Mozarina Mendes Sousa ${ }^{1}$ \\ Marcel Pereira Pordeus ${ }^{2}$
}

RESUMO: Este estudo é um recorte da minha dissertação de mestrado, e contou com apoio de pesquisadores na formação das ideias aqui assentadas. Deste fato, esta pesquisa buscou verificar e apresentar como a contação de histórias, em geral, pode influenciar no processo de ensino e aprendizagem, proporcionando uma aprendizagem significativa, principalmente quando falamos em relação ao letramento que pode ser definido de maneira simplificada como a capacidade de usar diferentes tipos de material escrito. Apresentamos a opinião de professores e de alunos sobre o uso dessa importante ferramenta, que é a contação de história, e se ela influencia o interesse do aluno em seu desempenho escolar, principalmente no que tange à leitura e à escrita. Apresentamos dois estudos aplicados na Escola Municipal de Educação Infantil Francisco Araújo, no município de Maracanaú-CE. Um estudo quantitativo sobre a opinião dos professores da área de linguagens e códigos sobre a influência do uso de contação de história no letramento dos alunos. Através dos resultados podemos concluir que estamos diante de uma poderosa ferramenta no auxílio do processo de ensino aprendizagem visando ao letramento infantil, que é a contação de história buscando a formação de alunos críticos e reflexivos que tiveram um grande enriquecimento educacional com o uso dessa ferramenta.

Palavras-chave: Letramento. Língua Portuguesa. Contação de História. Alfabetização.

\section{INTRODUÇÃO}

Desde o primeiro momento desta pesquisa ressaltamos o sentimento aprazível de produzir um estudo sobre aquilo que chamamos de Contação de Histórias. Destarte, e sem medo de generalizar os sentimentos do leitor, a clássica expressão "Era uma vez" funciona como um interruptor que imediatamente nos transporta ao mundo mágico do faz de conta e da fantasia.

Automaticamente, vem à tona lembranças lúdicas que personificam a própria infância e nos fazem mergulhar numa mistura de sensações e nostalgia. Personificar o herói, a mocinha ou mesmo o vilão das diversas histórias que povoaram o nosso imaginário

\footnotetext{
${ }^{I}$ Mestra em Ciências da Educação pela Universidad Interamericana. E-mail: mozarinamendes@gmail.com.

${ }^{2}$ Possui graduação em Letras pela Universidade Federal do Ceará. Mestre em Planejamento e Políticas

Públicas pela Universidade Estadual do Ceará. E-mail: marcel.pordeus@aluno.uece.br.
} 
infantil era a brincadeira mais usual e aquela que engrandecia a vida e nos fazia compreender o mundo a nossa volta, de uma maneira única e pessoal.

Ressignificar o mundo real, aquele que diz respeito à dimensão adulta, através das brincadeiras, brinquedos e historinhas infantis foi o grande desafio que permeou a infância dessa pesquisadora e, possivelmente, de todos aqueles que hoje leem esse trabalho. De forma geral, ousa-se dizer que é uníssono entre a totalidade dos educadores que arriscam refletir acerca do tema, que a disseminação da literatura, a partir da tradição oral ou escrita, através da contação de histórias, é um caminho que leva a criança a desenvolver a imaginação, emoções e sentimentos de forma prazerosa e significativa. É importante para a formação de qualquer criança ouvir muitas e muitas histórias. É através dos livros e contos infantis que a criança enfoca a importância de ouvir, contar e recontar.

Como prática essencial para o desenvolvimento lúdico e criativo da criança, a contação de histórias resulta em uma prática essencial, permitindo além da aprendizagem, que a criança, desde pequena, possa sentir a necessidade de experimentar sonhos, suas fantasias e seus encantos por meio da arte. É na fase infantil que se consolida a formação do caráter, com a vivência das primeiras experiências de vida, construção da personalidade e da consciência.

Aquilo que concebemos como Educar, Cuidar e Brincar e que sustenta qualquer orientação dada à Educação Infantil neste país, existe sob a égide do conceito de Ludicidade, e deve ser entendido como um instrumento pedagógico capaz de inserir a criança na Cultura, na Sociedade e na Educação.

$\mathrm{Na}$ Educação Infantil devemos facilitar a aprendizagem, utilizando atividades lúdicas que criem um ambientes agradáveis para favorecer o processo de aquisição de autonomia de aprendizagem. Para tanto, o saber escolar deve ser valorizado socialmente. A aprendizagem e a interação devem ser processos dinâmicos e criativos através de histórias, brincadeiras, musicalidade e outras atividades.

Uma mesma "historinha", para distintas culturas, pode ter diferentes significados, o que equivale a dizer que é preciso ponderar o contexto social em que se insere o objeto de nossa análise. Nessa perspectiva e entendendo a Contação de Histórias como uma ferramenta essencialmente lúdica e promotora de significado pedagógico, percebemos que é através dela que podemos permear vivências internas e dialogá-las com a realidade externa e real. 
Em suma, o "Contar Histórias" é um instrumento valoroso e facilitador da interação com o meio, pois opera como um dispositivo educativo democrático, capaz de produzir um mesmo sentimento, ainda que contextualizado, em crianças de distintas classes sociais e estamentos políticos. Nesse segmento, a criança deve fazer parte de uma cultura que a estimule o pensar, o sentir, o expressar e o experienciar, fatores que são componentes da narrativa de histórias e que despertam a sensibilidade, a emoção e o autoconhecimento, na mesma medida em que a ensina, instrui e a prepara para a vida.

\section{FUNDAMENTAÇÃO TEÓRICA}

De forma geral, este momento da pesquisa diz respeito à comunhão teórica entre as inquietações que motivaram o respectivo desafio intelectual e o leque de trabalhos, ensaios e afins que contemplam um paradigma formado e estabelecido acerca do objeto deste estudo. Em outras palavras, é na Fundamentação Teórica que se conversa com outros autores a respeito dos caminhos científicos que se pode percorrer.

Destarte, e de acordo com Mello (2006, p. 86),

[...] a fundamentação teórica apresentada deve servir de base para a análise e interpretação dos dados coletados na fase de elaboração do relatório final [...] dessa forma, os dados apresentados devem ser interpretados à luz das teorias existentes.

Nesse viés, toda teoria utilizada deve orientar a totalidade das fases da pesquisa, pois, como uma verdadeira fonte de saber, a ela se vai constantemente na medida em que se tem sede. Assim, e somente a partir desse momento, é que o andamento da pesquisa se delimita e ilumina o que carece de compreensão.

Segundo Theodoro e Otoni (2010), a prática da contação de histórias é um costume decrépito, observado muito antes de Jesus Cristo, versando sobre as origens da sociedade humana e revelando uma das primeiras manifestações culturais do homem, o qual é mantido por diferentes povos e repassado por inúmeras gerações.

Inclinando para a informalidade do objeto, Mateus e Silva (2017) informam que a existência das histórias é algo muito antigo, que antecede o desenvolvimento e até mesmo a utilização da escrita.

O ofício de contar histórias é remoto [...] e por ele se perpetua a literatura oral, comunicando de indivíduo a indivíduo e de povo a povo o que os homens, através das idades, têm selecionado da sua experiência como mais indispensável à vida (MEIRELES, 1979, p. 4I). 
Prosseguindo e retomando o paradigma histórico da Literatura Infantil (século XVII), Charles Perrault revela à sociedade de então, histórias densas e repletas de moralidade social. $\mathrm{O}$ autor citado, retirando toda crueldade e a estética nefasta (obscenidade, canibalismo assassinado e outros atos) que caracterizavam as narrativas folclóricas contadas pelos camponeses para assustar adultos e crianças de então, escreveu Os Contos da Mamãe Gansa, um emaranhado de contos paralelos que dão origem às clássicas histórias da "Bela Adormecida", "Chapeuzinho Vermelho", "O Gato de Botas", “As Fadas”, “A Gata Borralheira”, "Henrique do Topete” e "O Pequeno Polegar”.

Desde o seu surgimento, em meados do século XVII, a literatura infantil vem sendo permeada de preconceitos, rótulos e banalizações acerca de sua importância, função pedagógica e/ou artística, pois surgiu em um confronto com a literatura não infantil, ou seja, aquela consumida pelo público adulto e, como tal, classificada como hierarquicamente superior. Destarte, sua transição à dimensão infantil foi conflituosa.

Segundo Coelho (200o), anteriormente as crianças liam e ouviam as literaturas dos adultos, existindo uma distinção hierárquica ao acesso a essas histórias. As crianças burguesas tinham acesso aos clássicos, enquanto as pobres conheciam apenas os contos folclóricos e as lendas populares. As histórias foram adaptadas para o mundo infantil somente no século XVII e XVIII, quando as crianças deixaram de ser tratadas como adultos em miniaturas e passaram a ser vistas como seres em formação.

De acordo com Zilberman (2010), na criação da literatura infantil houve uma preocupação com essa nova faixa etária que estava sendo reconhecida na sociedade da época. Essa mudança aconteceu devido ao novo modelo familiar burguês, decorrente de um núcleo unicelular, com a preocupação de manter sua privacidade e estimular o carinho entre seus membros.

Esse novo reconhecimento da infância gerou uma maior união familiar, mas também serviu como instrumento de controle e manipulação do desenvolvimento cognitivo e emocional das crianças. Ainda com base no modelo de infância estabelecido, surgiu a necessidade de reformular a escola existente àquela época e a literatura infantil recém-criada, que exercia um papel importante nessa nova fase da sociedade, o de criar novos costumes e passar valores às crianças

No caminho percorrido, à procura de uma literatura adequada para a infância e juventude, observaram-se duas tendências próximas daquelas que já informavam a leitura dos pequenos: dos clássicos, fizeram-se adaptações; do folclore, houve a 
apropriação dos contos de fadas - até então quase nunca voltados especificamente para a criança (CUNHA, 1999, p. 23).

Nessa transição da literatura adulta para a infantil, percebe-se a adaptação das histórias e não a sua criação. A literatura agora não é utilizada simplesmente para a contação de histórias, ela ganha uma finalidade educacional e controladora de condutas e ideologias. Nessa mudança, o adulto fortalece o seu desejo de superioridade, tendo o poder sobre a criança, que exerce uma função inútil do ponto de vista econômico, sendo somente um consumidor, tornando-se um ser mais frágil e dependente (ZILBERMAN, 2003). Essa superioridade passou a ser exercida e desenvolvida na instituição escolar.

De acordo com Sousa e Strauss (2014), os primeiros livros infantis foram escritos por pedagogos, com o objetivo pedagógico tradicional, pois a escolarização obrigatória e a importância da educação visavam somente o desenvolvimento social, esquecendo o indivíduo em si. Candido (1995, p. 245) traduz em poucas palavras o que há de se compreender quanto à literatura infantil, bem como com a literatura como um todo e da relação que ela estabelece com a dimensão do educativo: “[...] toda obra literária é, antes de tudo, uma espécie de objeto construído [...] é grande o poder humanizador dessa construção."

Dado isso, percebe-se que as histórias, além de encantarem, representam uma forma de comunicação e transmissão de conhecimento existente no uso da oralidade, na escrita, nos costumes e na cultura expressa em sentimentos. Toda realidade é, portanto, manifestada pelo simples ato de contar uma história.

\section{I HISTÓRIAS E LITERATURA INFANTIL NO BRASIL}

Segundo Zilberman e Lajolo (1988, p. 17), no Brasil, “[...] os clássicos europeus forneciam o material para as adaptações e traduções que precederam à produção brasileira de literatura infantil."

De acordo com os autores citados, foi em I8o8, com a implantação da Imprensa Régia, que se iniciou oficialmente a circulação dos livros infantis, sendo o primeiro momento da literatura infantil brasileira caracterizado pela adaptação de livros europeus em versões "abrasileiradas" de textos e de autores clássicos dos séculos XVII, XVIII e XIX (LAJOLO; ZILBERMAN, 2оIо). 
Cunha (1987), por sua vez, afirma que a literatura infantil brasileira surgiu como obras pedagógicas e adaptações de produções portuguesas, demonstrando a dependência típica das colônias e o conformismo político de então.

Segundo Becker (200I), a Literatura Infantil no Brasil pode ser compreendida em quatro fases distintas, mas complementares na história e na sistematização de sua estrutura. A Primeira Fase compreende o início do século XX e caracteriza-se pelo compromisso político com a modernização e com a difusão do nacionalismo. Nessa fase, a literatura infantil é ferramenta para a produção de uma cultura eminentemente nacional.

A Segunda Fase, por sua vez, compreende o recorte cronológico entre 1920 e 1945 e destaca um momento de emergência do analfabetismo que faz surgir o "escolanovismo" (Escola Nova) como resposta ao quadro de Educação defasada que emergia de um atraso estrutural vigente.

A Terceira Fase é apontada pelo período compreendido entre as décadas de 1950 e I960 e por um momento educacional conhecido como "Reforma de Capanema", cujas transformações eclodiram na Lei de Diretrizes e Bases da Educação Nacional de 196i. Todavia e diante da Ditadura que surgira no respectivo momento, a Literatura infantil assumiu um caráter conservador e mais uma vez mergulhou no caráter patriótico.

A recuperação do folclore oral, representado em muitos momentos pelas "modinhas infantis”, pelas canções de ninar e pelas brincadeiras de roda caracterizam o quarto momento da literatura infantil que, outro não, produz um ambiente múltiplo e permite uma multiplicidade de temas e escritores.

Assim e em um primeiro momento, autores como Carlos Jansen (Contos seletos das mil e uma noites), Figueiredo Pimentel (Contos da Carochinha), Coelho Neto, Olavo Bilac e Tales de Andrade iniciam a cena brasileira de literatura marcadamente infantil, passando com destaque por Monteiro Lobato (início do séc. XX), e desaguando em Ana Maria Machado, Ruth Rocha, Ziraldo, Joel Rufino dos Santos, Eliardo França e Lígia Bojunga igualmente realçáveis na década de 1970.

A partir da década de 1970, a Literatura Infantil sofre uma virada temática e passa a se sustentar em novos dogmas da educação: a valorização da criatividade, da independência e da emoção infantil, o chamado, pensamento crítico e segundo Silveira (I997, p.I49), "[...] e com ênfase à criança ativa, participante, não-conformista." Mesmo reconhecido como adaptador de clássicos estrangeiros como 
Monteiro Lobato destacou-se como grande inaugurador da Literatura Infantil no país, com histórias autorais e contextualizadas à realidade brasileira. Paulista e pertencente à Escola pré-modernista do século XX, Lobato escreveu o primeiro livro autoral em ig2I (A menina do Nariz arrebitado); porém sua obra mais famosa são as histórias do Sítio do Pica-Pau Amarelo e seus habitantes.

\subsection{SURGIMENTO DAS ARTES E A CONTAÇÃO DE HISTÓRIAS NO CURRÍCULO ESCOLAR}

Em meados de 1816 foi instaurada a Escola Nacional de Belas-Artes, e marca o início da educação artística brasileira. $\mathrm{O}$ ensino da arte, conforme contemplamos hoje, passou por várias transformações e adaptações históricas e culturais que ao longo do tempo deram origem aos ideais e convicções que compõem a sociedade atual.

A Escola Nacional de Belas-Artes reproduzia no Brasil traços culturais seguindo os padrões europeus, a burguesia econômica e intelectualizada era a única classe que se beneficiava destes segmentos, visto que outras manifestações artísticas que seguiam aos formatos dos modelos de referência eram desprezadas.

Pautadas no autoritarismo e domínio de novas técnicas, como o traço geométrico, o ensino da arte passa a ser desenvolvido nas escolas tradicionais, com uma progressiva mudança das ideologias, cujo objetivo central era a formação disciplinar para a vida profissional. A Escola Nova, em meados de 1950, exerce influências sobre a arte, prezando nesta instância apenas a simplicidade e a inventividade dos alunos, fato que gerou certo consentimento, em que o processo se justapôs ao resultado final (a eficiência superou a eficácia).

O ensino artístico se torna propriamente componente curricular, com a propagação da Lei $\mathrm{n}^{\circ} 5.692$ de 1971, mas se desdobrando basicamente em ornamentações da escola, embelezamento de datas cívicas e atividades descontextualizadas. Somente com a publicação da Lei de Diretrizes e Bases (LBD) 9.394/96 seguida pelos Parâmetros Curriculares Nacionais (PCNs) e Diretrizes Curriculares Nacionais de Educação Infantil (DCNEI), que a arte se eleva à condição de linguagem significativa, com equivalência agora às demais disciplinas mediante seu caráter de saber indispensável que associa as práticas de produção, proveito e reflexão. 
$\mathrm{Na}$ sociedade, a arte pode manifestar-se em diferentes funções. Pode contemplar na ação de contar histórias, educar, provocar questionamentos; pode significar a realidade ou censurá-la; ser manifestação dos sentimentos do artista, do sonho, imaginação ou fervor religioso; e pode também ser desprovida de função alguma, bastando-se por si mesma. Quando entra em contato com o público, pode também gerar interpretações muito diferentes das pretendidas pelo artista. Mas pode-se dizer que, de forma geral, "[...] as manifestações artísticas possuem em comum seu caráter estético" (BOZZANO; FRENDA, 2013, p. II).

A arte é concebida como uma manifestação abstrata rigorosamente humana de expressar comportamentos, emoções, pensamentos, historicidade e valores atingindo também a beleza, a comunicação e as linguagens múltiplas como a contação de história, a dança, as artes cênicas, a música, a oralidade e a escrita, a escultura, a arquitetura, dentre outros. Assim sendo, desde a fase infantil o ensino da arte deve ser valorizado e estimulado, sendo reconhecido como Patrimônio Cultural da Humanidade, porque é na infância que a criança inicia suas descobertas iniciais, primeiras curiosidades, interesses, habilidades e progressos em geral concernentes à formação integral do sujeito.

\section{METODOLOGIAS E RECURSOS PARA A CONTAÇÃO DE HISTÓRIAS}

As pessoas contam histórias há séculos para explorar ideias e dar sentido a suas experiências. Deste fato, compartilhar histórias é tão natural para os seres humanos quanto comer e dormir. Algumas das histórias que contamos hoje foram transmitidas de geração em geração, enquanto outras são novas que nós mesmos criamos.

Para se tornar um exímio contador de histórias não é tarefa fácil, porque além de saber contar, deve-se também encantar. Esta postura exige habilidade, técnica e disposição para oferecer o melhor do talento do contador de histórias, existem também pessoas que possuem o dom (talento nato), para as quais o esforço para fascinar e prender a atenção do público é menor do que para aqueles que necessitam de capacitação para alcançar o mesmo patamar. Entretanto, são requisitos fundamentais para o desempenho desta atividade a familiaridade com as histórias e a incorporação da mesma. Schermack (2012) tem um olhar muito poético para a contação de história, para ele:

$\mathrm{Na}$ contação de história os ouvintes ingressam nos pensamentos secretos do narrador porque descrever uma história é como revelar um segredo, tornando-os conhecedores dos mistérios e saberes que uma história carrega. A história narrada 
traz em seu bojo uma vertente poética, representada por símbolos, imagens e objetos, que ganha vida na medida em que a história se desenvolve. Enquanto o contador ordena as informações, através das escolhas linguísticas que realiza, o interesse do ouvinte vai sendo despertado. $O$ que está sendo dito pelo narrador, de forma gradativa, vai aproximando-o da plateia (SCHERMACK, 2012, p. o5o6).

Como retratamos um contador de história em potencial? Ele não é um ator que decora os textos de um personagem, não deve ser considerado como um ser excelso e inigualável, a comum que traz sua experiência de vida transformando-a em uma arte performática (expressão artística em que o contador é parte da obra, fundindo a vida com a experiência).

A Literatura no âmbito da educação formal é também falar da literatura, é também contação de história, uma vez que a consolidação das práticas de alfabetização e letramento se dá no campo linguístico de codificação e decodificação das palavras, envolvendo também a leitura de mundo conforme defende Paulo Freire. "A leitura do mundo precede a leitura da palavra, daí que à posterior leitura, desta não possa prescindir da continuidade da leitura daquele. Linguagem e realidade se prendem dinamicamente" (FREIRE, I989, p. 09).

Embora a Educação Infantil não tenha a função de alfabetizar a criança, ela é uma etapa fundamental para o desenvolvimento de habilidades ligadas à oralidade, cognição, desenvolvimento psicomotor, criatividade, imaginação, raciocínio, noção espacial, interação, socialização, dentre outras, que serão fundamentais para que o processo de leitura e escrita aconteça posteriormente de forma mais natural e significativa. Bernardino e Souza (20II) corroboram essa ideia dizendo que:

O fracasso escolar no ensino fundamental se refere ao desenvolvimento do gosto da leitura e formação de leitores, que recai sobre a forma como o professor está trabalhando a relação do livro com o aluno. A literatura não está recebendo um estímulo adequado e a contação de histórias é uma alternativa para que os alunos tenham uma experiência positiva com a leitura, e não uma tarefa rotineira escolar que transforma a leitura e a literatura em simples instrumentos para as provas, afastando o aluno do prazer de ler (BERNARDINO; SOUZA, 2011, p. 236).

Nesse sentido, a contação de história deve necessariamente iniciar-se pela Educação Infantil, aproveitando todos os recursos que ela abrange, linguagem, escuta ativa, fantasia, teatro, música e acesso a livros infantis de qualidade, despertando prazer ao ouvir e ao mesmo tempo preparando a criança para o universo aprazível da leitura. O contato com os livros na educação infantil exerce muita influência no desenvolvimento da criança, na medida em que desperta o gosto pela leitura, amplia os conhecimentos e estimula habilidades ligadas à oralidade e escrita. 
A leitura de histórias, contos, fábulas, poemas e cordéis, entre outros, realizada pelo professor, possibilita a presença da literatura na Educação Infantil, introduz a criança na escrita além do desenvolvimento do gosto pela leitura, do estímulo à imaginação e da ampliação do conhecimento de mundo. $\mathrm{O}$ professor atua como mediador entre os textos e as crianças, propicia a vinculação com livros, com diferentes gêneros literários, a riqueza variada de ilustrações e a escrita, a aprendizagem da direção da escrita e as formas corretas de manipulação de livros.

\section{CONCLUSÃO}

As pesquisas teóricas realizadas neste trabalho trouxeram informações pertinentes para a prática pedagógica da contação de histórias na Educação Infantil e Ensino Fundamental, destacando-se as aprendizagens múltiplas; a socialização; os desenvolvimentos físico, psicológico, oral, artístico e emocional; assim como formação pessoal e social, em que há respeito à infância e à formação integral do sujeito.

Ressalta-se o papel do professor-mediador que atua como um agente motivacional de seus alunos, facilitando e estimulando seu aluno a conhecer novos horizontes, conhecer a si e situar-se no meio em que vive por meio da experiência, do conhecimento e das habilidades gerais, entretanto, a prática pedagógica sozinha não consegue desenvolver todo este processo, deve haver conformidade entre qualificação profissional, condições favoráveis de trabalho e políticas públicas de incentivo, incluindo o resgate das tradições orais.

Tais circunstâncias operaram conexões de direcionamento e de transmissão de conhecimento intelectual, pois conseguiram desenvolver, no âmbito do estudo, novas noções de aprendizagem vinculadas ao objeto da contação de histórias, mas ainda, reforçar velhos princípios e valores que existem na essência dessa prática educativa.

A pesquisa revelou, portanto, que a necessidade de se cuidar dos aspectos lúdicos do processo de ensino e aprendizagem, bem como a necessidade de empoderamento dos sujeitos pela conquista do letramento, da leitura e da compreensão da literatura como instrumento de descoberta do mundo. O ensino através da contação de histórias (orais ou escritas) estabelece-se como uma alternativa eficaz e se justifica pelo pela indispensabilidade de uma Pedagogia Inclusiva, contextualiza e carregada de afetividade. 
Assim, levando em conta que o jovem moderno é distinto e vulnerável às diferenças e à fluidez das relações sociais, há que se operar um ensino voltado para o cognitivo, em que o desenvolvimento seja dinâmico, constante e expressado em meio ao exercício pleno da cidadania.

A contação de histórias, nesse viés, torna-se mais uma via de transmissão de saber, pois permite ao discente a sensação de conhecer, ouvir, conversar, se interessar, se envolver e ser sensível ao mundo que o circunda. Em suma, é por esse processo que o educando ganha condições reais de desenvolvimento social e constrói, de forma muito consciente, sua cidadania já nos primeiros anos de sua formação. Contudo, há que se pontuar, neste momento conclusivo, acerca da formação do professor e, como já foi colocado em algum momento deste texto, como esse profissional pode compor o processo de ensino e aprendizagem de forma efetiva e marcante na vida dos pequenos discentes que mergulham no mundo da Literatura.

\section{REFERÊNCIAS}

BECKER, Celia Doris. História da literatura infantil brasileira. In: SARAIVA, Juracy Assmann (org.). Literatura e Alfabetização, do plano do choro ao plano da ação. Porto Alegre: Artes Médicas, 200I. p.35-4I.

BERNARDINO, Andreza Dalla; SOUZA, Linete Oliveira de. A contação de histórias como estratégia pedagógica na Educação Infantil e no Ensino Fundamental. Educare et educare. Revista de educação. São Paulo, v o6, nํำ ${ }^{2}$, p. 235-249, jul./dez. 20II. Disponível em: http://www.scielo.br. Acesso em: 22 nov. 2017.

BOZZANO, Hugo, FRENDA, Perla. O que é arte. In: BOZZANO, Hugo. Arte em Interação. Volume Único. São Paulo. IBEP. 2013.

BRASIL. Ministério da Educação. Referencial Curricular Nacional Para a Educação Infantil. v. 3. Brasília: MEC/SEF, 1998.

BRASIL. Educação integral/educação integrada em tempo integral: concepções e práticas na educação brasileira. Brasília: MEC, 2009, I48 p.

BRASIL. Constituição de 1988. Constituição da República Federativa do Brasil. Brasília: Senado Federal, Centro Gráfico, 292, 1988.

BRASIL. Mais educação. Brasília: MEC, 2012, s/p. Disponível em: http://portal.mec.gov.br. Acesso em: 16 out. 2017. 
BRASIL. Comitê Nacional de Educação em Direitos Humanos. Plano Nacional de Educação em Direitos Humanos. Brasília: Secretaria Especial dos Direitos Humanos, Ministério da Educação, Ministério da Justiça, UNESCO, 2006.

BRASIL. Lei de Diretrizes e Bases da Educação Nacional - LDB.LEI noo. 9394/96. Brasília: Ministério da Educação, 1996.

CANDIDO, A. O direito à literatura. In: Vários escritos. 3. ed. São Paulo: Duas Cidades, 1995. p. 235-263.

COELHO, Nelly Novaes. Literatura Infantil: Teoria, análise, didática. São Paulo: Moderna, 2000.

CUNHA, Maria Antonieta Antunes Cunha. Literatura Infantil: teoria e prática. 6 ed. São Paulo: Ática, 1987.

FIGUEIREDO, Marcelo. Teoria Geral do Estado. 2. ed. São Paulo: Atlas, $200 ı$.

FREIRE, P. Educação e Mudança. Rio de Janeiro: Paz e Terra, I98ı.

FREIRE, Paulo. Pedagogia da Autonomia: saberes necessários à prática educativa. São Paulo: Paz e Terra, 1996.

LAJOLO, Marisa, ZILBERMAN, Regina. Um Brasil para crianças: para conhecer a literatura infantil brasileira: história, autores e textos. São Paulo: Global, 1988.

LAJOLO, Marisa, ZILBERMAN, Regina. Literatura Infantil brasileira: História e Histórias. São Paulo: Ática, 2010.

MACHADO, Ana Maria. Como e Por que ler os Clássicos Universais desde Cedo. Rio de Janeiro: Objetiva, 2002.

SCHERMACK, Keila de Quadros. A contação de histórias como arte performática na era digital: convivência em mundos de encantamento. 2012. Disponível em: http://ebooks.pucrs.br/edipucrs/anais/ IIICILLIJ/Trabalhos/

Trabalhos/Sio/keilaschermack.pdf. Acesso em: I2 ago. 2018.

SILVEIRA, R. Ela ensina com amor e carinho, mas toda enfezada, danada da vida. In: Cultura, mídia e educação: Educação e Realidade. Rio Grande do Sul: v. 22, n. 02, jul./dez. 1997 .

STRAUSS, Anselm e CORBIN, Juliet. Pesquisa Qualitativa. Técnicas e procedimentos para o desenvolvimento de teoria fundamentada. 2. ed. Porto Alegre: Artmed, 2008. Série Métodos de pesquisa. 
ZILBERMAN, Regina. A literatura infantil na escola. 4 ed. São Paulo: Global, 1985.

ZILBERMAN, R.L.G. STRIEDER, R. A inclusão escolar e os desafios da aprendizagem. Brasília: Caderno de Pesquisa, 2010. 